\title{
A State-of-the-Art Review on the Integration of Building Information Modeling (BIM) and Geographic Information System (GIS)
}

\author{
Xin Liu ${ }^{1, *}$, Xiangyu Wang ${ }^{1,2}$, Graeme Wright ${ }^{3}$, Jack C. P. Cheng ${ }^{4}$, Xiao Li $^{5}$ and Rui Liu ${ }^{6}$ \\ 1 Australasian Joint Research Centre for Building Information Modelling, School of Built Environment, \\ Curtin University, Bentley 6102, Western Australia, Australia; xiangyu.wang@curtin.edu.au \\ 2 International Scholar, Department of Housing and Interior Design, Kyung Hee University, \\ Seoul 02447, Korea \\ 3 Research and Development, Curtin University, Bentley 6102, Western Australia, Australia; \\ g.l.wright@curtin.edu.au \\ 4 Department of Civil \& Environmental Engineering, Hong Kong University of Science and Technology, \\ Hong Kong, China; cejcheng@ust.hk \\ 5 School of Construction Management and Real Estate, Chongqing University, Chongqing 400030, China; \\ xiao.li@cqu.edu.cn \\ 6 School of Construction Management, University of Florida, Gainesville, FL 32611, USA; liurui@ufl.edu \\ * Correspondence: xin.liu@curtin.edu.au; Tel.: +61-449-920-138
}

Academic Editor: Wolfgang Kainz

Received: 24 November 2016; Accepted: 15 February 2017; Published: 20 February 2017

\begin{abstract}
The integration of Building Information Modeling (BIM) and Geographic Information System (GIS) has been identified as a promising but challenging topic to transform information towards the generation of knowledge and intelligence. Achievement of integrating these two concepts and enabling technologies will have a significant impact on solving problems in the civil, building and infrastructure sectors. However, since GIS and BIM were originally developed for different purposes, numerous challenges are being encountered for the integration. To better understand these two different domains, this paper reviews the development and dissimilarities of GIS and BIM, the existing integration methods, and investigates their potential in various applications. This study shows that the integration methods are developed for various reasons and aim to solve different problems. The parameters influencing the choice can be summarized and named as "EEEF" criteria: effectiveness, extensibility, effort, and flexibility. Compared with other methods, semantic web technologies provide a promising and generalized integration solution. However, the biggest challenges of this method are the large efforts required at early stage and the isolated development of ontologies within one particular domain. The isolation problem also applies to other methods. Therefore, openness is the key of the success of BIM and GIS integration.
\end{abstract}

Keywords: Geographic Information System; Building Information Modeling; City Geography Markup Language; industry foundation classes; semantic web; Extract Transform Load

\section{Introduction}

Building Information Modeling (BIM) is a digital representation of a facility's physical and functional characters [1]. It is based on technology incorporating information in three dimensions (3D) and integrates the necessary information required by Architecture, Engineering, Construction and Facilities Management (AEC/FM).

In contrast, Geographic Information Science (GIS) is developed to manage and analyze spatial data, which is based on geomatics technologies. GIS as a technology/system allows the storage of 
spatial information in the relational database, and, as a science, is also beyond data storage system. The attribute information associated with spatial features stored in the database allows for further spatial analysis using both the spatial and non-spatial attributes.

BIM includes very rich and detailed construction information from both geometric and semantic views, however, it does not include the surrounding information [2]. Bansal [3] illustrated the limitations of BIM in the spatial planning for construction. Sometimes spatial information are necessary by a BIM system for environmental evaluation, resource arrangement and safety analysis [4]. For example, topographic information, which is essential to the spatial planning of gravity dam construction, can only be accessed in GIS. Optimization of tower cranes' location on construction site is another classic example that BIM requires spatial information [5].

GIS is able to implement spatial analysis based on the functional and physical spatial relationship of outdoor environment at large spatial scale; however, it lacks detailed and comprehensive digital repository of building information [6]. For example, road authorities are not only interested in the road planning information and the context of the road, but also work on the standardized "as designed" road information, which is not available in a traditional geospatial database, but is stored in a BIM system. In addition, BIM can provide detailed design of pipeline network and detailed supplier information of every item in a building. Such information will strongly further the traditional GIS management and analysis of pipeline network, such as optimal design of a gas transmission network and supply chain management [7]. Furthermore, traditional noise analysis is separately conducted either indoor or outdoor, the integration of BIM and GIS system can develop seamless noise-mapping at any spatial scale [8].

The integration system of BIM and GIS enables the effective management of information in various stages of a project's life cycle, namely planning, design, construction, operation, and maintenance. The information at any spatial and temporal scale can be available in such system for different applications. Effective management of heterogeneous information from different sources can also provide essential supports for decision-making.

In the past, numerous challenges, such as the development with two different standards and different ways of thinking on the research questions [9], were encountered for the integration of GIS and BIM, and initial attempts have been tried. While in the early days of BIM and GIS integration, users all tried to solve their problem within their own domains [10]. GIS users tried to integrate BIM data or CAD data into a GIS system, while BIM users employed spatial information in BIM system. These attempts can be viewed as applying "glue" to stick the two [11]. Currently, solutions to the integration become more "compromised", and can be categorized into three levels: data level, process level and application level. These will be further explored in Section 5.

This section sets the scene by giving an overview of existing research and initiatives concerning the integration of GIS and BIM. Section 2 discusses the development of GIS, and Section 3 focuses on the conceptualization and functionalities of BIM. Section 4 finds that while GIS and BIM have been developed for different purposes in two different domains, they do share some common components and it is necessary for them to be integrated in certain applications. Section 5 describes three different levels of GIS and BIM integration methods. The review of Section 6 leads to further discussion of the existing applications of GIS and BIM integration. The conclusions Section brings all this analysis together, suggesting new directions and future focus points.

\section{Introduction and Development of Geographic Information System}

GIS is a decision-support system, which has all the features of an information system. The major difference between GIS and other information systems is that the GIS data are geo-referenced [12]. The location information or spatial information and all the other attributes that are related to this location are important components of GIS. Such information is important to the further spatial and temporal analysis [13]. Normally, the spatial information represents the reality through an abstract model [14], and includes coordinates, the spatial relationship between features and additional 
non-spatial attributes. The key research topics of GIS can be summarized as: locations, conditions, trends, patterns and models [15].

Truly 3D GIS has become more practical with the development of the above topics. Although in many cases 2D GIS suffices, the requirement of handling the complex internal structures of mine sites, buildings, and retail complexes drives the development of a more detailed 3D model $[16,17]$. To enrich more details into a 3D model, the 3D spatial relationships between different objects in the model need to be identified [18].

Among all the efforts, City Geography Markup Language (CityGML) currently is the most comprehensive standard exchange of urban information in geospatial domain [19]. CityGML is also one of the most prominent semantic 3D modeling formats and represents a significant step towards the integration of BIM and GIS [20-22].

CityGML is defined as a common semantic information model that represents the 3D objects in the geospatial context and can be shared by different applications [23]. It aims to structure the information about cities and contextual features as a whole [22]. However, CityGML is not specifically adapted to the facility design process.

One of the ways to manage objects and data by CityGML is to introduce the concept of Level Of Detail (LOD). It includes LOD0 (Region and Landscape), LOD1 (city and region), LOD2 (city, city district and project), LOD3 (city district, exterior architectural model and landmark) and LOD4 (landmark and interior architectural model) [24], and the higher levels use increasing structural complexity and accuracy [25,26], de grees of resolution [23], and accuracies and minimal dimensions of objects [24].

Compared with the first generation of CityGML [22], the second generation [23] offers richer 3D modeling structures for not only buildings, but also tunnels and bridges, which is more closer to the BIM infrastructure. Other new features include: a Level Of Detail 0 (LOD0) representation for building, new attributes, new mechanism, and a grouping mechanism for generic attributes [19].

\section{Building Information Modeling}

BIM comprises a set of interacting policies, processes and technologies with the aim to develop "a methodology to manage the essential facility design and project data in digital format throughout the facility's life cycle" [27]. For instance, it can identify and clarify the existing relationship between architectural, structure layout and mechanical, electrical and hydraulic service by systematically coupling project components together [28].

One of the significant features of BIM is that it enables transparent information sharing and management of the facilities $[29,30]$ and interactive operations for the clients or users through the entire project life cycle [1]. Such information includes the digital representation of both physical and functional components of a facility.

BIM can be as uncomplicated as 3D CAD technologies that is not only able to design and represent a facility, but can also be enriched by providing additional dimensions, such as cost, schedule, accessibility, safety, loGIStics, security, sustainability, maintainability, acoustics and energy simulation [31,32]. By incorporating these construction business functions, engineering analysis can be implemented at each stage of the lifecycle of the constructed facility. Therefore, it is clear that BIM is not just a piece of software, but also a process that contributes to the workflow and project delivery process [33]. However, despite the complex system into which BIM has been developed, in a real sense, a building is not designed as an isolated micro-scale item independent from the macro-scale built environment [34]. Furthermore, the limited capability for spatial inquiry and locating objects in large scale are another two limitations of BIM [35]. Therefore, a broader built environment view is essential for data management in modern construction management.

The buildingSmart Industrial Foundation Class (IFC), as the most comprehensive and popular exchange format for BIM within the industry, is designed to present the building context [36]. It is an established generic information exchange standard for BIM, and supported by most of the BIM 
software in the AEC industry [23]. Compared with CityGML, which is specified as Extensible Markup Language (XML), IFC is defined as the data modeling language EXPRESS [37], and the entities in IFC are referred by line number. IFC also has an XML version, IfCXML, which is XML based and can be exchanged over the Internet using web-services but is not as widely used as EXPRESS-based IFC. IFC is an object-oriented data schema and largely based on STEP technology (exchange of product model data). STEP addresses the product data representation and exchange among different domains, such as manufacturing, oil and gas, building construction, mechanical design, etc. In addition, some objects, for example road objects, are not provided by IFC; however, supports and tools are available to develop new standardized road objects [38]. Recently, in the latest version, IFC 4 [39], further steps have been made towards the interoperability with GIS by including new geographic elements, such as "IfcGeographicElement" and "IfcGeographicElementType".

As indicated by Tolmer, Castaing, Diab and Morand [24], the concept of LOD in IFC is different to those in CityGML, i.e., Level Of Development (LODt), and is used to monitor the design progress, without an ISO normalization as in CityGML. Generally, the description of the LODt definition can be given as: (1) LODt 100: only a symbol or other generic representation; (2) LODt 200: a generic system, object, or with approximate assembling information; (3) LODt 300: a specific system, object, or with detailed assembling information; (4) LODt 400: a specific system, object, or with detailed assembling information with fabrication and installation information; and (5) LODt 500: a field verified representation with all the information in LODt 400 [40]. However, from certain perspectives, LOD and LODt have strong correlation and indicate the same thing in BIM. One example of the variation of the LODt from 100 to 400 is shown in Figure 1.

As an open format, IFC has become one of the most successful interoperable tools to exchange information across different platforms. However, limitations were identified in terms of expression range, information partition, and multi-interpolation on same information [41]. Pauwels, Van Deursen, Verstraeten, De Roo, De Meyer, Van de Walle and Van Campenhout [41] also demonstrated that semantic web technology provides a way to solve these limitations, which will be further discussed in Section 5.2.

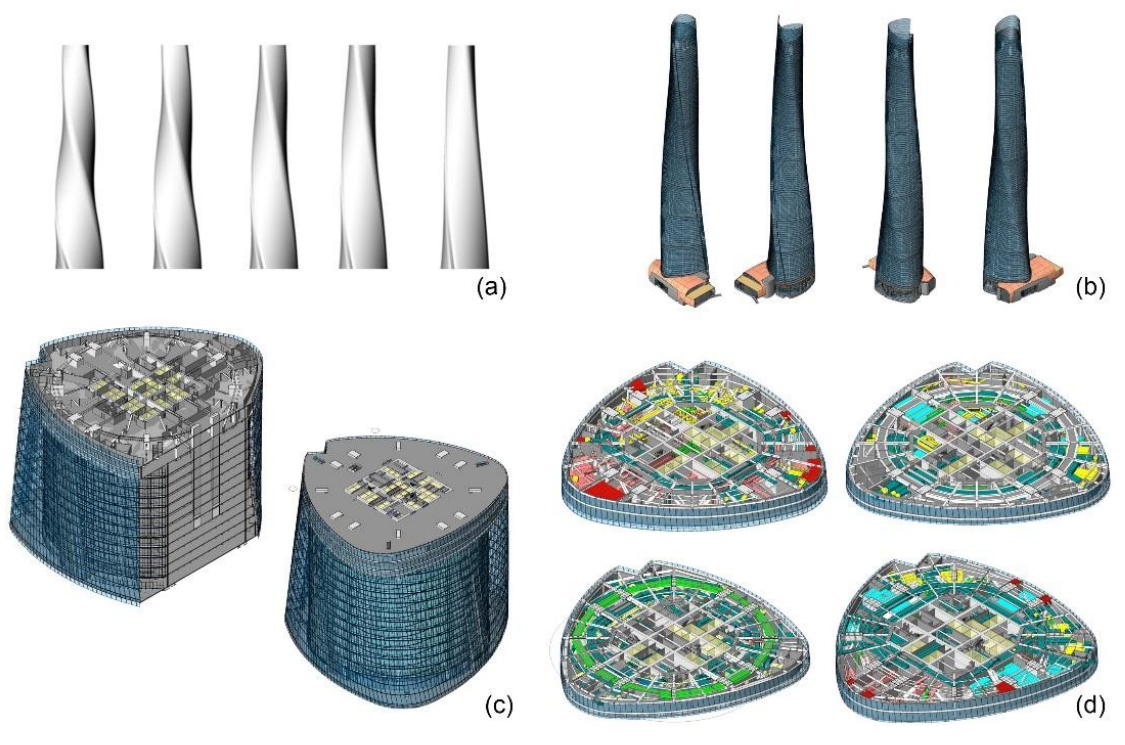

Figure 1. (a-d) An example to represent the different Level Of Development (LODt) of Trade Center building from 100 to 400 , respectively.

CityGML and IFC share some similarities. For example, both are object-based and they define some similar entities. Donkers [42] stated that some models that adhere to the CityGML are consistent with those in IFC to a large extent in term of geometrics. However, in addition to the different modeling languages they use and the amount of information included, many dissimilarities between 
the two standards also exist. For example, the object in IFC is defined by one or more of the following: Boundary Representation (BRep), Swept Solid, and Constructive Solid Geometry (CSG). In contrast, all objects are represented by BRep [36]. Moreover, the LOD is defined differently in IFC and CityGML and transformation of IFC to CityGML requires a full LODs matching in CityGML. In addition, IFC contains much more detailed information than CityGML. Therefore, a complete mapping between IFC and CityGML is not easy. As part of BIM and GIS families, they also share other common BIM and GIS dissimilarities and mismatches.

\section{BIM-GIS Dissimilarities and Mismatches}

BIM and GIS interpret 3D modeling from two different perspectives: GIS focuses more on real world modeling, while BIM is more focused on the design process. Therefore, in CityGML, for example, a wall is represented as surface for each room separately, while, in IFC, a wall is a volume object, which is shared between rooms and the exterior shell [43]. The real world modeling of GIS is driven by the requirements of mapping tasks, while the design modeling of BIM is based on the representation of geometric design and construction details [44]. GIS often focuses on the geographical information and shape of buildings and building components from a geographical perspective. In contrast, BIM often focuses on the detailed building components and project information, such as cost and schedule from an architecture and construction perspective [45].

Furthermore, although there are substantial works towards as-built model reconstruction [46], BIM is still mainly developed to represent objects that do not exist prior to the generation of the model. In contract, GIS aims to model the objects that already exist around us, and the models should be recognized as easily as possible. The mismatched information is one of the challenges to integrate BIM and GIS.

Computer-based GIS has been developed since late 1960s, while the concept of GIS and its manual application were adopted about 100 year earlier [47]. Over the past few decades, GIS has been developed from an application-led technology to a problem solving science, which includes principles, techniques and analysis methods [48]. In contrast, BIM is much younger than GIS. The first formal discussion on the potential of BIM was introduced in the late 1980s and early 1990s [49]. In the last few years, although the number of BIM studies on analysis methods has been increasing, BIM can still only be viewed as an application-led technology.

Generally, their dissimilarities and mismatches can be summarized as: different users, different application focuses, different developmental stages, different spatial scales, different coordinate system, different semantic and geometric representations, different levels of granularity, and different information storage and access methods. Although these two concepts/technologies have matured in different ways, the overlap between them has become bigger recently (Figure 2). With the recent demand for merging outdoor and indoor applications for different purposes, attempts have been made to design methods and tools to integrate building models within a geospatial context. However, barriers coming from these dissimilarities and mismatches exist for the integration between the two different concepts and their respective enabling systems.

To overcome the barriers and challenges, open and collaborative attitude and work are critical among all GIS and BIM users. From previous experience, the openness and collaboration can be achieved by: (1) demand driven, for example, smart city development [50]; (2) frequent communication [51]; and (3) government initiatives [9].

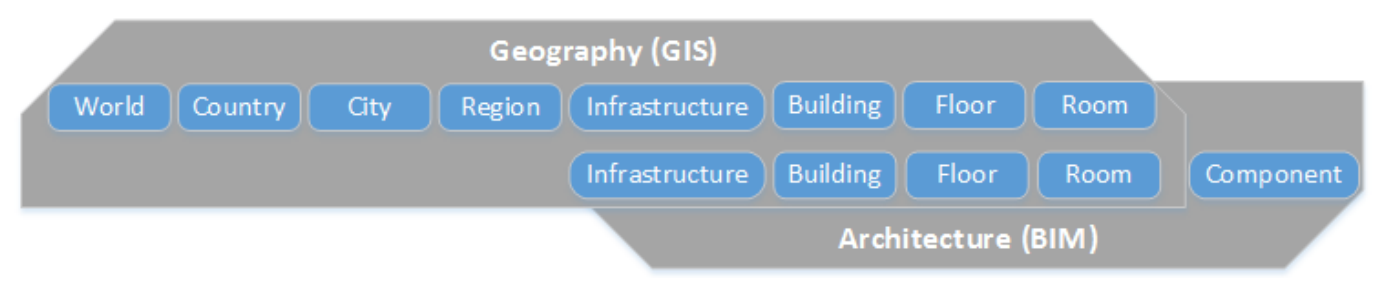

Figure 2. Overlap between the fields of GIS and BIM. 


\section{Integrating Building Models with Geospatial Context}

Previous integration methods can be classified in different ways: semantic or geometric level; unidirectional or bidirectional methods; and commercial or open source software. Amirebrahimi, Rajabifard, Mendis and Ngo [6] also summarized that previous works on the integration of GIS and BIM can be categorized into three levels: data level, process level and application level. However, a sufficient and detailed illustration of previous works on these three levels was missing. This study adopts this way of classification and further discusses previous BIM and GIS integration works from these three different levels.

\subsection{BIM and GIS Integration at Data Level}

The integration of BIM and GIS at data level normally involves the introduction of new standards, revision of old standards, or the conversion/translation of data format.

\subsubsection{New Standards and Models}

The Open Geospatial Consortium (OGC) Land And Infrastructure Domain Working Group (LandInfraDWG) was chartered in 2013 to work on the integration of LandXML and CAD-based land information with other OGC standards by better understanding the nature of LandXML [52]. During this process, InfraGML was proposed as a successor of LandXML. Although originally from the spatial world, the OGC LandInfra SWG group has begun to work closely with buildingSMART International and its IFC for BIM interoperability. This new standard will be more easily integrated with CityGML, and thereby able to work as a bridge between BIM and GIS.

The InfraGML covers the areas of land development and civil engineering infrastructure facilities, with potential to include transport networks, terrain, land parcels, drainage, wastewater, and water distribution systems in the future [53].

IndoorGML was developed by the IndoorGML Standard Working Group [54] in an OGC GML 3.2 application schema. The working group aims to introduce an application for indoor navigation, but the new standard can also work as a data source for the interior topology of buildings, thereby complementing the existing standards, such as IFC and CityGML [54]. Some information in IndoorGML can be directly derived from IFC or CityGML LoD 4, while some feature types defined in IndoorGML have the potential to be used by IFC and CityGML in future [55].

In this standard, geometric, semantic and topology information of indoor spaces has been well described. Based on the IndoorGML standard, a mature system with editor and viewer functions was developed [56]. Particularly, this system can support BIM data, with potential to support geospatial information.

Unified Modeling Language (UML) was also used to develop a new model-Unified Building Model (UBM), in which most elements and objects are derived from both IFC and CityGML [44,57]. UBM works as an intermediate model to relate BIM and GIS. This model is built based on IFC and CityGML, and can be revised for different applications. It aims low and is flexible; therefore, could avoid the information loss for one particular use.

The QUASY (Quartierdaten-Managementsystem) project aims to develop a new 3D semantic building model, which is dedicated to urban development [58]. It has many similar features as CityGML, but becomes more flexible, due to the application of variants (QuVariants). The variants can indicate different things, such as volume, surface, and curve geometry; detailed semantic information on building components; and a parametric description for future instantiation. Part of the objects in IFC were mapping to the QUASY using IfcWallModificator.

The introduction of new standard or model can fundamentally and revolutionarily solve the integration problem, as it avoids the barrier between the two domains. However, the emerging standards and models can only provide solution from one particular view, for example, building, infrastructure and indoor space. There is no single standard can cover all the aspects in a region. This is 
partly because the development of a new standard or model is a very time and cost consuming process. In addition, for different reasons, information loss (actively or passively) is an unavoidable problem in the new developed standard or model, especially for those maturing standards and models with big ambition to include everything in a region. The review work found that focused projects are more easily to become successful, in terms of information loss, flexibility and labor cost.

\subsubsection{Conversion, Translation and Extension of Existing Standards}

As IFC and CityGML are the most popular and representative standards in BIM and GIS domains, respectively, a large number of efforts were made to convert, translate or extend them to be compatible by each other. However, based on the description in Section 3, the current CityGML and IFC standards are still not sufficient to support the structure information of the entire built environment lifecycle for urban and infrastructure projects. Therefore, further steps are required to provide solutions to the data exchange problems. The existing methods can be summarized into two categories: manual and semi-automatic, and no method can fully automatize the conversion process.

The integration between CityGML and IFC has always been considered as an important way to implement the complete picture of 3D modeling at different levels of detail [59]. Several previous projects have been conducted to achieve this goal $[10,43,60,61]$, and most of them are with a focus on the exchange of geometry. The geometry conversion from IFC to CityGML is normally performed to lower LODs in CityGML [10]. There are also a few research efforts focusing on the integration of semantic information between GIS and BIM by extending and mapping CityGML and IFC schemas [37,45,62].

El-Mekawy, Östman and Hijazi [57] listed and discussed the differences between the two standards and the possibility of the conversion between the different classes/entities. Similarly, de Laat and van Berlo [10] listed the classes in IFC that could be used in GIS system, and extend the CityGML as GeoBIM extension to support IFC semantics and geometries. It was demonstrated in an XML Schema file (XSD) and as a UML class diagram. This was implemented on the BIM server [63]. The interactive relationship between the theoretical model and the software implementation on BIMserver makes this theoretical GeoBIM extension very robust for practical use. The framework of BIMserver is to enable the storage, maintenance, query and centralization of information from different data sources and encourage collaboration among participants [64]. It includes an Eclipse Modeling Framework (EMF) model [65] of IFC, a Berkeley DB database [66] and communication interface using web technologies, such as Representational State Transfer (REST), Simple Object Access Protocol (SOAP) and web user interface [10]. The IFC Engine DLL library [67] and the CityGML4j java library [68] are connected to the EMF interface and compose CityGML files [10]. However, BIMserver only allows unidirectional translation from IFC to CityGML.

In order for IFC and CityGML to be compatible in one system, Geiger, et al. [69] simplified the complexity of the IFC model in terms of both geometry and semantics. This study was implemented on the IFCExplorer, which is a software package developed to integrate, visualize and analyzes the spatially referenced data at Karlsruhe Institute of Technology [70].

Generally, the manual conversion/translation between IFC and CityGML normally involves the steps: (1) semantic filtering; (2) exterior shell computing; (3) incorporation of building installation; (4) geometric refinements; and (5) semantic refinements [42]. This is one of the classic frameworks on IFC and CityGML conversion/translation.

Zlatanova, et al. [71] stated that one of the limitations of the conversion between IFC and CityGML is the missing semantics. Even if the semantic information is complete after conversion, the original meaning of the attributes does not retain [72]. However, this does not mean the conversion of geometry will always be easy. Transferring from CityGML to IFC is more difficult in terms of both semantic information and building geometry [35]. Two of the possible solutions are a better defined surface type in CityGML and the improvement of the "IfcSpaces" in IFC [42]. "IfcSpaces" and "IfcSlab" are two key layers between the conversion of CityGML and IFC. 
Recently, a semi-automatic way of BIM and GIS data conversion/translation was implemented by the Extract Transform Load (ETL) process, which extracts the homogeneous data from the source systems and load the data into data warehouse by transforming the data into proper format or structure. In order to improve the loading time, the BIM object geometry information is normally processed by ETL before being represented in the integrated system [73]. A step-by-step description on how to integrate BIM data into a spatial information model by ETL was demonstrated by Rafiee, Dias, Fruijtier and Scholten [2]. Kang and Hong [72] furthered this study by providing a more detailed and structured framework using similar principles. Normally, the process starts with the geometry conversion, which is followed by the Global ID allocation. Global ID will be used to automate the semantic translation [2]. The semantic information in the original data is mapping into a structure that destination data format can recognize.

One of the most popular and successful commercial platforms applying ETL is Feature Manipulation Engine (FME) [74]. The spatial ETL used by FME is not a one-way conversion tool. Same as IFCExplorer, it supports a bidirectional reading and writing between IFC and CityGML [42]. Two other large companies adopting spatial ETL process to integrate heterogeneous data sources are ESRI and Oracle, and the functions are called ArcGIS Data Interoperability [75] and Oracle Spatial with Spatial ETL [76], respectively.

Theoretically, both geometric and semantic information should stay relatively consistent, when translated between IFC and CityGML by ETL. However, this depends on the data knowledge of the operator on both GIS and BIM, especially for sematic information conversion. In addition, there is normally no coordination information stored in IFC, and an additional step (for example, LocalCoordinateSystemSetter in FME) is required to set the original location of the model in IFC.

The mapping process during the ETL can be flexible, and it enables both full and customized translation between BIM and GIS data. One the other hand, the model mapping process is costly in terms of both time and money, although this mapping work is not as costly as those at deeper standard level. Therefore, ETL tools are good for bulk data conversion, which translates large volume data in batch. Admittedly, errors are unavoidable sometimes during the model mapping and interpretation stage, as human processing involves and the irreconcilable difference between the two standards. For example, it is not easy to fully interpret the contiguous space boundaries in IFC by ETL process, which cannot be easily solved by manual conversion either [77]. Moreover, another disadvantage of ETL is that it cannot implement on-demand and real-time data conversion. Although many previous studies have been done on this topic, quick response ETL is still not achieved at practical level.

\subsection{BIM and GIS Integration at Process Level}

\subsubsection{Semantic Web Technologies}

The integration at process level will not change the data format and structure from both sides, and "they simultaneously remain live and distinct" [6]. BIM and GIS have different contents and data structures, and BIM normally has much more information than GIS. In order to develop a seamless integration system, a reference ontology as part of semantic web technologies can be used to store and represent the differences. Reference ontology is not a new category of ontologies, but is designed to take a global view of many domains by extending and specializing high-level ontologies [78].

The ultimate goal of semantic web is to "allow data to be shared effectively by wider communities, and to be processed automatically by tools as well as manually" [79]. Therefore, semantic web has a natural ability to integrate information from different sources. It aims to provide machine accessible semantics to annotations using rich conceptual schemas-ontologies [11]. Ontologies define the terms in annotations using a set of pre-defined concepts, and transform them into semantic annotations. Resource Description Framework (RDF) works more like a framework to manage and represent ontologies. 
Deng, Cheng and Anumba [36] summarized a framework of IFC and CityGML integration using reference ontology: (1) transformation of geometry; (2) translation of coordination system; (3) development of schema mediation using ontology; and (4) harmonization of different LoDs in CityGML. There is ongoing work that aims to develop a harmonized framework for networked and distributed concept libraries [80]. In the context of the Linked Open Data initiative, the concept of semantic mash-up scenarios was intensively explored by the proposed system. In this work, BIM and GIS will be able to remain commensal by adopting the techniques of IFC for GIS (IFG) data model [81] and buildingSMART Data Dictionary (formerly the International Framework for Dictionaries or IFD) [82] and semantic web technologies.

Similar to the ongoing work from Beetz [80], there were a number of similar researches conducted on the topic of distributed models under the concept of the semantic web, RDF and ontologies. This is one of the most active areas being explored by researchers from both GIS and BIM. Mignard and Nicolle [35] built an evolutive ontology and an architecture of Urban Facility Management. There is no widely accepted definition of evolutive ontology. Generally, it stands for an ontology that becomes adaptive to arisen changes in one domain and maintains consistency of itself and its depending artifacts [83]. This platform is an extension of facility management ACTIVe3D [84] by defining the spatial, temporal and multi-representation concepts. In addition, Karan, et al. [85] introduced a similar work frame as Beetz's, however, a more detailed framework and workflow has been presented in their study.

Semantic web technologies based integration methods enable the bidirectional conversion between BIM and GIS. They are also more flexible than other methods, as the defined ontologies can be available for future use. In addition, such an approach preserves the semantic information specified in both domains, while still enabling data integration on a semantic level. However, semantic web technologies are still developing and maturing, especially for the enrichment of globally agreed ontology definition. Currently, the development of semantic data models is mainly a manual and time-costly process, especially at early stage [86]. One of the potential solution is to develop a converter at sever-side using programing tools, such as PHP scripting language [85]. In addition, the isolated and independent development of ontologies within one particular domain is another constraints of heterogeneous data fusion.

\subsubsection{Services-Based Methods}

Another attempt to integrate BIM and GIS information is through OGC map services by the 3D Information Management (3DIM) Domain Working Group. The purpose of Web Services test bed phase 4 (OWS-4) project was to demonstrate that the BIM-GIS could be integrated over the Internet using web-services at a process level, and without developing new web-service types to address the integration issues. The OGC OWS-4 participants [87] have either applied the existing OGC web services, such as Web Feature Server (WFS), or developed new types of components in the Open Geospatial Service Architecture to integrate BIM. Finally, a compromised Transactional Web Feature Service (WFS-T for BIM) was applied to serve features from both IFC and CityGML.

Similarly, Lapierre and Cote [22] used CityGML, WFS, and 3D Viewer to develop a web-based solution to manage city data. Hagedorn and Dollner [88] integrated GIS, CAD, and BIM Data to build the Virtual 3D City Model, which is also based on the web service supported by the Onuma System.

The system performance of services-based method is normally effective, in terms of both semantic and geometric conversion, and less information loss can be identified. However, such system normally has low flexibility and extensibility [72]. An expensive and specialized solution is required when problems occur, such as the low efficient mapping process due to the non-optimized programming code in the system. Moreover, the services-based method also shares similar disadvantages to other integration methods at process level. Since the process level integration always involves human intervention, low productivity is the drawback at the early stage of integration system development. 


\subsection{BIM and GIS Integration at Application Level}

The last group of integration methods is at application level. At this level, both source data and object data are not changed, and no service or ontology is developed. This type of studies was normally implemented to serve a specific use case. For example, noise information separately calculated from BIM and GIS, works as medium to exchange and integrate the necessary information between the two systems [8]. There is another study adopted information as medium between BIM and GIS systems [89]. In this study, the information required by GIS and further spatial analysis was extracted by a customized plug-in, which is available in any commercial BIM software. Then, the information was stored in the central database (e.g., MS Access).

Moreover, in addition to the information and customized tools (plug-in), schema is another option to work as integration medium. Green Building XML (gbXML) was adopted as intermediate data format between GIS and BIM by Niu, et al. [90]. The useful information in BIM was extracted, simplified, and stored as gbXML file, which was converted to KML and COLLADA after the energy simulation, then presented on the Google Earth. The integration methods at application level solve the problem from one particular angle, and normally cannot be adopted by other methods. Generally, this type of methods will not be costly in terms of both time and labor.

\subsection{Comparison of Integration Solutions}

A number of previous or on-going studies have been discussed in previous Sections. The methods used in these studies were introduced due to various reasons and aimed to solve different problems. Therefore, the selection of integration method is highly a problem driven question. Based on the systematic literature review on the previous integration solutions, the parameters influencing the choice can be summarized and named as "EEEF" criteria: effectiveness (less information loss), extensibility (high degree of openness), effort (time/labor/money cost), and flexibility (the possibility of one result that can be applied by other studies). The pros and cons of each solution are listed in Table 1.

Table 1. Comparison of integration solutions by "EEEF" criteria.

\begin{tabular}{ccccc}
\hline Integration Methods & Effectiveness & Extensibility & Effort & Flexibility \\
\hline $\begin{array}{c}\text { New standards and models } \\
\text { extersion, translation and } \\
\text { standards (manual) }\end{array}$ & case by case & case by case & case by case & case by case \\
$\begin{array}{c}\text { Conversion, translation and } \\
\text { extension of existing }\end{array}$ & medium & high & high & medium \\
$\begin{array}{c}\text { standards (semi-automatic) } \\
\text { Semantic web technologies }\end{array}$ & medium & medium & medium & medium \\
$\begin{array}{c}\text { Services-based methods } \\
\text { Application focused methods }\end{array}$ & case by case & high & high & medium \\
\hline
\end{tabular}

The conclusion in Table 1 is based on the nature of the methods and the comparison of the case studies illustrated in this Section. The spatial scales of new standards or models range from indoor space (IndoorGML), infrastructure (InfraGML) to city (QUASY project) with completely different application purposes and LODs. Therefore, the "EEEF" of new standards and new models development highly depends on their ambitions. If the new model aims to solve one particular small and focused problem, the overall evaluation of "EEEF" can be very satisfying. On the other hand, if the model or standard aims to cover all the aspects of BIM and GIS, the risk is normally high. However, any efforts towards new standard development should be encouraged, as it could solve the integration problem fundamentally and revolutionarily. It takes time and effort to achieve anything worth doing.

The conversion, translation and extension of existing standards, either manual or semi-automatic, normally involve semantic filtering (ignoring or mapping) process; therefore, certain level of information loss is not avoidable. The aim of both semantic web technologies and services-based 
methods is to enable data sharing, rather than converting existing standards or developing new ones. Thus, little information loss can be seen during the integration at process level. As data filtering process might be involved in the application focused methods, information loss might happen.

Manual conversion, translation and extension of existing standards and semantic web technologies end up with new entities development, such as GeoBIM, and ontology, which can be easily available and further enriched by future studies. The semi-automatic integration, such as ETL, focuses on the process description (data format is changed during the integration process), and the process can vary among different applications. Therefore, the developed ETL process is not extensible by all the future applications. As web-service technology is becoming mature and service-based integration is "extensively specialized problem-solving method" [72], it shows weak potiential in extensiblity.

As most integration works at process level require extensive human intervention, low productivity is the drawback at the early stage of such integration system development. Compared with manual conversion, translation and extension of existing standards, semi-automatic methods only require human intervention during the mapping stage. Since source data, object data, service and ontology are neither changed nor developed by application focused methods, it requires least effort and has least flexibility, compared with others. Due to the specialized problem-solving nature of service-based integration, it also has low flexibility. The converted, translated and extended standards, mapping relationship in ETL process, or the new ontology developed from one study all require certain level of revision, in order to be used by another study. These three methods balance the practical application and new integration knowledge generation. The latter feature provides an opportunity to deliver adaptive results.

\section{Applications of GIS and BIM Integration}

\subsection{D Cadastre}

$3 \mathrm{D}$ cadaster is an important application of BIM and GIS integration in the recent times. Traditionally, cadaster is based on a 2D parcel description with associated legal status and property right information. However, such description can be inaccurate, especially for the complex building structures with multi-levels above and under the ground [91]. BIM can provide much more detailed information for cadaster purposes. However, sometimes the information in BIM can be too detailed, and simplification process is required. Other information, such as ownership and transaction history, is not available in BIM [92]. Therefore, many studies were implemented to translate the information between BIM and GIS to develop a seamless 3D cadaster system [91-93]. However, the implementation of 3D cadaster is not only a technical issue, but also involves organizational and legal challenges [53,93].

\subsection{Location-Based Services (LBS) and Navigation}

Location based services (LBS) stand for providing services based on the geographical location which is determined by a mobile device [94]. The localized services can be both triggered and user-requested, and are stimulated by a number of applications such as emergency response [95]. Different from traditional contingency plan [96], current technologies enable that emergency operations can be timely and dynamically navigated to a target building on a GIS platform; however, when within a building or construction site, the architectural and engineering details, such as building interior, water supply and electricity supply, are required to make effective decisions [22].

The integration of BIM and LBS extends the traditional 2D LBS to 3D, especially within a building [97]. Shayeganfar, et al. [98] presented a smart indoor navigation solution to enhance the indoor timely response. It combines the BIM and the user constraints using semantic web technologies. Hwang, Kang and Choi [56] and Zverovich, et al. [99] also developed an indoor navigation system, but put more focus on the tools development on BIM and GIS integration for indoor space. Besides the detailed representation of a building, such as the efforts on IndoorGML [54,56], the enhancement of an indoor navigation environment, by using radio frequency identification (RFID) or indoor wireless 
network, can also improve the timely and accurate indoor positioning [100]. Other applications of the integration of location-based services and BIM include measurement of pedestrian traffic in a building [101], road monitoring and reporting [102], and construction activity tracking [103]. However, privacy preservation is required for the BIM and LBS system, considering that various stakeholders may have access rights to the shared information across the project environment $[104,105]$.

\subsection{Asset Management}

In general, asset management requires systematic processes in the fields of operation, maintenance and renovation. Large asset owners are becoming aware of the advantages of applying information management techniques in reaching more comprehensive solutions [106]. A more informed asset-deployment decision will be made with the assistance of a fully functional asset management system with adequate and reliable information [107].

A GIS/BIM platform has been used for a preliminary feasibility study to estimate the cost of building a national road [108]. Park, Kang, Lee and Seo [108] developed a system that employs BIM and GIS systems with three modules that estimate construction cost, land acquisition cost and operations and maintenance cost, separately, in order to assist reasonable decision making for the optimized route selection. Moreover, Krämer and Peris [109] introduced the GIS and BIM integration work at Botanic Garden, Berlin. It aims to improve the sustainable management of facilities in the garden and information services for visitors and scientists.

Asset management work order processes highly rely on the sustainable supply chain management. One example about such study was presented in Irizarry, Karan and Jalaei [89] study, in which BIM and GIS were integrated into a unique system to visualize the construction supply chain process and keep track of the material status. In addition, Liu and Issa [51] integrated GIS and BIM for 3D visualization of sub-surface pipelines in connection with the building utilities for facilities management purposes.

\subsection{Heritage Management}

Recent development of techniques has facilitated the capture and management process for architectural heritage data, which includes radiometric, geometric, spatial and multi-temporal data [9]. One of the capabilities of BIM is to support 3D models derived from design data [110]. In addition, the three important concepts related to efficient information management in three dimensions for any historic building are: (a) segmentation; (b) structuring the hierarchical relationships; and (c) semantic enrichment [9]. These concepts are composed in a typical pipeline for as-built BIM generation [111]. In Dore and Murphy [112] study, the architectural elements represented by parametric objects were mapped onto the data captured by laser scan or photogrammetric survey. The surrounding environmental information, such as street view, transportation and cadastral information, was represented by CityGML, and was integrated with the 3D heritage.

Furthermore, SanJosé-Alonso, et al. [113] and Centofanti, et al. [114] introduced semantically-rich 3D objects in a GIS environment. In addition, a safety monitoring system was developed on a GIS platform to manage the cultural heritage in a historical street in Taiwan [115]. In this system, the 3D information of historical buildings and the corresponding surrounding environment was represented by laser scanning.

\subsection{Site Selection and Layout Plan}

BIM allows project planners to immerse the realistic view of the construction site and evaluate the potential hazards by using information embedded in three-dimensional models. The detailed component information in the predesigned BIM can also assist with decisions during the site plan stage [116]. In contrast, GIS provides the spatial context view of the site and the quantitative assessment of environmental impacts [117]. GIS can support evaluation of on-site material accessibility and detection of spatial-temporal conflicts for construction site material layout [118]. Furthermore, the 
visualization capability of GIS, specifically the three-dimensions and navigation system, is also able to utilize the site selection and layout plan [119,120].

The application of integrated GIS and BIM systems to facilitate site selection can be attributed into two different areas: site for equipment and site for construction. Irizarry and Karan [5] presented a function to optimize the number and locations of cranes on a construction site by considering their locations and geometric layout of loads. Bansal [3] made full use of the advantages of GIS, such as topography modeling and geospatial analysis, and the advantages of BIM, such as linking the execution schedule with a three-dimensional (3D) model, to facilitate the space planning and time-space conflict identification. Bansal [121] also presented an integrated GIS and BIM system to predict places with high potential for accidents and activities to improve the site layout plan. In addition, Bansal [3] developed an integrated system that enables time-space conflict identification and proposes solutions prior to construction.

\subsection{Urban Environment Analysis}

The recent fast development of ICTs becomes one of the driving force in the urban transformation and development of smart city [122]. Admittedly, smart city is not all about ICT technology, however, ICTs provide important digital and communication infrastructure of smart city [123]. As part of ICTs, the integration of BIM and GIS helps establish a spatially seamless digital infrastructure, which is a critical foundation of smart city development. In Neirotti, et al. [124] study, many potential application domains of smart city were illustrated, including urban environment analysis, which aims to improve the sustainable resources and infrastructure management in a city by employing BIM, GIS or other ICTs.

Thiis and Hjelseth [125] proposed an approach based on BIM and GIS to enable climatic adaptation of buildings. Bansal and Pal [126] proposed a method for direct sunlight visualization to calculate the amount of sunlight received on different faces of a building by integrating BIM with GIS. Energy required on an urban scale level was also forecasted in the integrated 3D city system [127], and the impacts of different levels of building details on the energy demand were also illustrated in this study. Potential also exists in identifying the relationship among environmental impact, urban density and solar gains, thereby estimating the necessary building energy consumption [2,128]. GIS and BIM can help with investigating the dynamic relationship between weather conditions, urban geometry, and individual building's properties. Such a system will improve urban planning and building design in terms of energy optimization. Niu, Pan and Zhao [90] improved it by developing a web-based system to visualize and inspect energy consumption at both building and urban level. In addition, Castro-Lacouture, et al. [129] presented a conceptual GIS-BIM framework about algae power generation system to improve the energy consumption at the level of urban neighborhood.

As an industry-driven collaborative research project, STREAMER aims to reduce the energy cost and carbon emission in the EU by $50 \%$ in next decade. In this project, the whole lifecycle information of the buildings in healthcare districts was stored and managed in a BIM/GIS system. This system used optimized semantics driven design methods and interoperable tools to analyze the design, construction, operation and maintenance information of healthcare district buildings [130].

Traditionally, flood damage is evaluated separately at two different scales: building and city. Due to the emergence of new technologies and tools to integrate BIM and GIS, they could be assessed in one integrated system. Such system enables the detailed evaluation and prediction of flood damage to the buildings in whole city $[6,20]$. Such efforts can increase a city's adaptability to climate change.

\subsection{Safety}

Zhou, et al. [131] stated that the integration of BIM and GIS enables a more complete consideration of construction safety. Bansal [121] presents the limitation of BIM simulation of the construction process to prevent hazards, such as a lack of topographic modeling and geospatial analysis. GIS helps with evaluation of the potential environmental hazards surrounding by providing an overview of 
construction projects and their relationship with their surrounding environment [132]. For example, a GIS based navigable 3D animation was developed by Bansal [121] to predict the locations of potential hazards and activities required for safety planning purposes. The GIS database is also able to present and analyze hotspot locations of construction hazards [121]. On the other hand, BIM is able to present construction safety concerns using the information obtained from the design phase [133]. Zhang, et al. [134] developed automatic safety detection algorithms. The algorithms allow the analysis of the safety and hazards in the BIM system, and propose corresponding prevention methods.

Isikdag, Underwood and Aouad [96] introduced BIM and GIS system to develop fire response management operations, and this system also covered the topic of site selection. In this study, not only the semantic information of the building (such as floor plan and stories), but also the geometric information was applied to optimize the site selection and emergency response. Similar application can also be identified in Tashakkori, et al. [135] study. In addition, safe route analysis was implemented to evaluate the outdoor walking environment in the United States. An explicit description of the neighborhood walkability of an elementary school was provided by integrating BIM and GIS [136].

Moreover, the development of surface and subsurface data integration has been driven by a series of disasters with underground excavations [137-139]. The integration of BIM and geospatial models enables the modeling of surface and subsurface features, such as buildings and geology, in an integrated framework [140]. This integrated framework will not only benefit the planning and design process for surface and subsurface structure construction, but also make transparent the risk management [138].

\section{Conclusions and Directions for Future Research}

BIM and GIS interpret 3D modeling from two different perspectives, and they have matured in different ways. Currently, the development of BIM and GIS already has some overlapping areas. Meanwhile, the gaps between the two spaces are becoming gradually smaller. Consequentially, limitations and potentials exist at the same time for the future integration of BIM and GIS. GIS can be enriched with its true 3D by being integrated with BIM. The geometric and semantic information transferred from building modeling to a geospatial context will positively influence a series of current activities, such as site selection, safety management and environment impact assessment.

Although geometric transferring is not necessarily easy, the semantic level conversion is more challenging. In the last few years, the increasing amount of effort on the integration of BIM and GIS from a semantic point of view is significant. However, the problem of information loss and change is still serious during the information exchange. This is partially due to the different development purposes of the two systems. Especially, the relatively younger concept of BIM and its standard IFC have not satisfied the requirements of standards yet: competitiveness, conformity, and connectivity [141]. In an IFC model, additional semantics are appreciated to indicate how some aspects are to be modeled in CityGML. "IfcSpaces" and "IfcSlab" are two key layers between the conversion of CityGML and IFC. On the other hand, the GIS world needs to continuously devote time to the development of a more open, stable standard for sharing spatial information with building information.

Three levels of BIM and GIS integration methods have been illustrated in this paper. The selection of integration method should vary from one study to another, and "EEEF" criteria (effectiveness, extensibility, effort and flexibility) were introduced to assess the methods in each group. Ambitious new standard development work can be complex and information loss is commonly observed, due to the discrepancies between the types of classes and the different LODs in original and object schemas [72]. The risk can be significant reduced if the new developed model or standard is focused, less ambitious and application-oriented. Although the development of ambitious and more generalized new standard or model is still maturing, any effort towards this end should be encouraged, as it could fundamentally and revolutionarily solve the integration problem among heterogeneous datasets.

The application of semi-automatic conversion, translation and extension of existing standards is a good compromise among all the methods available, considering its low cost and the relatively good integration result. Compared with the manual conversion, semi-automatic methods require less effort 
by sacrificing the extensibility. This is because, theoretically, the semi-automatic methods have a work structure or workflow to be followed.

Due to the fast development of Internet technology, there are large amounts of system integration built with the help of new web technologies. Good integration results have been achieved by services-based methods in term of less information loss. However, due to its low flexibility and low extensibility, it is not as popular as semantic web technologies, which provide a more generalized integration solution. Nevertheless, it is also a costly method, especially at the early stage. Furthermore, the isolated and independent development of ontologies exacerbates the challenges faced by scientists and engineers from different domains. Admittedly, the future of BIM and GIS integration by semantic web technologies is still promising, as more people devote to this area.

The application focused methods require the least effort compared with other groups of methods. However, application focused methods normally cannot be easily adopted by others, since they were normally developed to solve a particular problem and are not generalized.

There are still many obstacles and challenges to the achievement of BIM and GIS integration. Mismatching information between the two is one of the most important factors. The mismatching information not only indicates the standard format difference, but also stands for different users, different application focuses, different developmental stages, different spatial scales, different coordinate system, different semantic and geometric representations, different levels of granularity, and different information storage and access methods.

Therefore, openness and collaboration are the keys of the success of BIM and GIS integration. This not only applies to new standard or ontology development, but also indicates the attitudes of people from different domains. Previous studies show that demand driven, frequent communication and government initiatives are the three key paths to achieve open and collaborative integration work between BIM and GIS. For example, the recent emerging smart city study requires people from both domains to collaboratively work together to develop seamless ICT infrastructure. This paper also presented a wide range of applications via integration of BIM and GIS, and indicates the enormous potential of it.

Acknowledgments: This research was undertaken with the benefit of a grant from the Australian Research Council Linkage Project (No. LP140100873).

Author Contributions: All authors contributed to the idea and concept of this systematic literature review. Xin Liu and Xiangyu Wang conducted the systematic literature review. Xin Liu and Graeme Wright performed the in-depth analysis and drafted the manuscript. Xin Liu, Jack C.P. Cheng and Xiao Li contributed to the further analysis and to the compilation of this paper. Rui Liu provided useful comments on the paper.

Conflicts of Interest: The authors declare no conflict of interest.

\section{References}

1. Wang, X.; Love, P.E.D.; Kim, M.J.; Park, C.-S.; Sing, C.-P.; Hou, L. A conceptual framework for integrating building information modeling with augmented reality. Autom. Constr. 2013, 34, 37-44. [CrossRef]

2. Rafiee, A.; Dias, E.; Fruijtier, S.; Scholten, H. From BIM to geo-analysis: View coverage and shadow analysis by BIM/GIS integration. Procedia Environ. Sci. 2014, 22, 397-402. [CrossRef]

3. Bansal, V. Use of GIS and topology in the identification and resolution of space conflicts. J. Comput. Civ. Eng. 2010, 25, 159-171. [CrossRef]

4. Yau, N.-J.; Tsai, M.-K.; Yulita, E.N. Improving efficiency for post-disaster transitional housing in indonesia: An exploratory case study. Disaster Prev. Manag. 2014, 23, 157-174. [CrossRef]

5. Irizarry, J.; Karan, E.P. Optimizing location of tower cranes on construction sites through GIS and BIM integration. J. Inf. Technol. Constr. (ITcon) 2012, 17, 351-366.

6. Amirebrahimi, S.; Rajabifard, A.; Mendis, P.; Ngo, T. A data model for integrating GIS and BIM for assessment and 3D visualisation of flood damage to building. Locate 2015, 15, 10-12.

7. Hijazi, I.; Ehlers, M.; Zlatanova, S.; Becker, T.; van Berlo, L. Initial investigations for modeling interior utilities within 3D geo context: Transforming ifc-interior utility to citygml/utilitynetworkade. In Advances in 3D Geo-Information Sciences; Springer: New York, NY, USA, 2011; pp. 95-113. 
8. Deng, Y.; Cheng, J.C.; Anumba, C. A framework for 3D traffic noise mapping using data from BIM and GIS integration. Struct. Infrastruct. Eng. 2016, 12, 1267-1280. [CrossRef]

9. Saygi, G.; Remondino, F. Management of architectural heritage information in BIM and GIS: State-of-the-art and future perspectives. Int. J. Herit. Digit. Era 2013, 2, 695-714. [CrossRef]

10. De Laat, R.; van Berlo, L. Integration of BIM and GIS: The development of the citygml GeoBIM extension. In Advances in 3D Geo-Information Sciences; Springer: New York, NY, USA, 2011; pp. 211-225.

11. Horrocks, I. Ontologies and the semantic web. Commun. ACM 2008, 51, 58-67. [CrossRef]

12. Stanton-Chapman, T.L.; Chapman, D.A. Using GIS to investigate the role of recreation and leisure activities in the prevention of emotional and behavioral disorders. Int. Rev. Res. Ment. Retard.: Dev. Epidemiol. Ment. Retard. Dev. Disabil. 2011, 33, 191-211.

13. Liu, X.; Shannon, J.; Voun, H.; Truijens, M.; Chi, H.-L.; Wang, X. Spatial and temporal analysis on the distribution of active radio-frequency identification (RFID) tracking accuracy with the kriging method. Sensors 2014, 14, 20451. [CrossRef] [PubMed]

14. Xiao, J.; Liu, H.; Luan, X.; Zhou, Z. The Design of a Map Database; Geoinformatics; International Society for Optics and Photonics: Munich, Germany, 2007.

15. Virmani, S.; Prasad, K.; Pande, S. Overview of GIS, GIS application in cropping system analysis-case studies in Asia. In Proceedings of the International Workshop on Harmonization of Databases for GIS Analysis of Cropping Systems in the Asia Region, Patancheru, India, 18-29 August 1997.

16. Becker, T.; Nagel, C.; Kolbe, T.H. A multilayered space-event model for navigation in indoor spaces. In $3 D$ Geo-Information Sciences; Springer: Heidelberg, Germany, 2009; pp. 61-77.

17. Boguslawski, P.; Gold, C.M.; Ledoux, H. Modelling and analysing 3D buildings with a primal/dual data structure. ISPRS J. Photogramm. Remote Sens. 2011, 66, 188-197. [CrossRef]

18. Stadler, A.; Kolbe, T.H. Spatio-semantic coherence in the integration of $3 \mathrm{~d}$ city models. In Proceedings of the 5th International Symposium on Spatial Data Quality, Enschede, The Netherlands, 13-15 June 2007.

19. Gröger, G.; Plümer, L. Citygml-interoperable semantic 3D city models. ISPRS J. Photogramm. Remote Sens. 2012, 71, 12-33. [CrossRef]

20. Amirebrahimi, S.; Rajabifard, A.; Mendis, P.; Ngo, T. A framework for a microscale flood damage assessment and visualization for a building using BIM-GIS integration. Int. J. Digit. Earth 2015, 43, 1-24. [CrossRef]

21. Hijazi, I.H.; Ehlers, M.; Zlatanova, S. Nibu: A new approach to representing and analysing interior utility networks within 3D geo-information systems. Int. J. Digit. Earth 2012, 5, 22-42. [CrossRef]

22. Lapierre, A.; Cote, P. Using Open Web Services for Urban Data Management: A Testbed Resulting from an OGC Initiative Offering Standard CAD/GIS/BIM Services. In Urban and Regional Data Management; Rumor, M., Coors, V., Fendel, E.M., Zlatanova, S., Eds.; Taylor and Francis Group: London, UK, 2008; pp. 381-393.

23. Gröger, G.; Kolbe, T.; Nagel, C.; Häfele, K. OGC City Geography Markup Language (Citygml) Encoding Standard v2. 0. OGC Doc, 12-019; Open Geospatial Consortium: Wayland, MA, USA, 2012.

24. Tolmer, C.-E.; Castaing, C.; Diab, Y.; Morand, D. Citygml and IFC: Going further than LOD. In Poceedings of the 2013 Digital Heritage International Congress (DigitalHeritage), Marseille, France, 28 October-1 November 2013.

25. Valentini, L.; Brovelli, M.A.; Zamboni, G. Multi-frame and multi-dimensional historical digital cities: The como example. Int. J. Digit. Earth 2014, 7, 336-350. [CrossRef]

26. Kolbe, T.H. Representing and exchanging 3D city models with citygml. In 3D Geo-Information Sciences; Springer: Heidelberg, Germany, 2009; pp. 15-31.

27. Penttilä, H. Describing the Changes in Architectural Information Technology to Understand Design Complexity and Free-form Architectural Expression. J. Inf. Technol. Constr. (ITcon) 2006, 11, 395-408.

28. Dossick, C.S.; Neff, G. Organizational divisions in BIM-enabled commercial construction. J. Constr. Eng. Manag. 2009, 136, 459-467. [CrossRef]

29. Wang, X.; Love, P.E. BIM+ AR: Onsite information sharing and communication via advanced visualization. In Proccedings of the 2012 IEEE 16th International Conference on Computer Supported Cooperative Work in Design (CSCWD), Wuhan, China, 23-25 May 2012; pp. 850-855.

30. Wang, X.; Truijens, M.; Hou, L.; Wang, Y.; Zhou, Y. Integrating augmented reality with building information modeling: Onsite construction process controlling for liquefied natural gas industry. Autom. Constr. 2014, 40, 96-105. [CrossRef] 
31. Taylor, J.E.; Bernstein, P.G. Paradigm trajectories of building information modeling practice in project networks. J. Manag. Eng. 2009, 25, 69-76. [CrossRef]

32. Aouad, G.; Lee, A.; Wu, S. Constructing the Future: Nd Modelling; Routledge: London, UK, 2006.

33. Hardin, B. BIM and Construction Management: Proven Tools, Methods, and Workflows; John Wiley \& Sons: New York, NY, USA, 2011.

34. Peters, E. BIM and geospatial information systems. In Handbook of Research on Building Information Modeling and Construction Informatics: Concepts and Technologies; IGI Global: Hershey, PA, USA, 2010; pp. 483-500.

35. Mignard, C.; Nicolle, C. Merging BIM and GIS using ontologies application to urban facility management in active3D. Comput. Ind. 2014, 65, 1276-1290. [CrossRef]

36. Deng, Y.; Cheng, J.C.; Anumba, C. Mapping between BIM and 3D GIS in different levels of detail using schema mediation and instance comparison. Autom. Constr. 2016, 67, 1-21. [CrossRef]

37. Borrmann, A.; Kolbe, T.; Donaubauer, A.; Steuer, H.; Jubierre, J.; Flurl, M. Multi-scale geometric-semantic modeling of shield tunnels for GIS and BIM applications. Comput.-Aid. Civ. Infrastruct. Eng. 2015, 30, 263-281. [CrossRef]

38. Bektas, E.; Luiten, B.; Böhms, M. Distributed modeling for road authorities. In Proceedings of the 30th CIB W78 International Conference, Beijing, China, 9-12 October 2013.

39. buildingSMART. Industry Foundation Classes Release 4 (IFC4). Available online: http://www. buildingsmart-tech.org/ifc/IFC4/final/html/ (accessed on 5 October 2016).

40. Bedrick, J. A level of development specification for BIM processes. AECbytes Viewp. Available online: http:/ /www.aecbytes.com/viewpoint/2013/issue_68.html (accessed on 23 May 2016).

41. Pauwels, P.; Van Deursen, D.; Verstraeten, R.; De Roo, J.; De Meyer, R.; Van de Walle, R.; Van Campenhout, J. A semantic rule checking environment for building performance checking. Autom. Constr. 2011, 20, 506-518. [CrossRef]

42. Donkers, S. Automatic Generation of Citygml lod3 Building Models from IFC Models; TU Delft, Delft University of Technology: Delft, The Netherlands, 2013.

43. Nagel, C.; Stadler, A.; Kolbe, T.H. Conceptual requirements for the automatic reconstruction of building information models from uninterpreted 3D models. Proc. Int. Arch. Photogramm. Remote Sens. Spat. Inf. Sci. 2009. [CrossRef]

44. El-Mekawy, M.; Östman, A.; Hijazi, I. A unified building model for 3D urban GIS. ISPRS Int. J. Geo-Inf. 2012, 1, 120-145. [CrossRef]

45. Cheng, J.C.P.; Deng, Y.C.; Anumba, C. Mapping BIM schema and 3D GIS schema semi-automatically utilizing linguistic and text mining techniques. J. Inf. Technol. Constr. (ITcon) 2015, 20, 193-212.

46. Volk, R.; Stengel, J.; Schultmann, F. Building information modeling (BIM) for existing buildings-Literature review and future needs. Autom. Constr. 2014, 38, 109-127. [CrossRef]

47. Coppock, J.T.; Rhind, D.W. The history of GIS. Geogr. Inf. Syst.: Princ. Appl. 1991, 1, $21-43$.

48. Longley, P. Geographic Information Systems and Science; John Wiley \& Sons: Hoboken, NJ, USA, 2005.

49. Eastman, C.M. Modeling of buildings: Evolution and concepts. Autom. Constr. 1992, 1, 99-109. [CrossRef]

50. Månsson, U. BIM \& GIS connectivity paves the way for really smart cities. Geoforum Perspektiv. 2016, 14. [CrossRef]

51. Liu, R.; Issa, R. 3D visualization of sub-surface pipelines in connection with the building utilities: Integrating GIS and BIM for facility management. In Computing in Civil Engineering (2012); ASCE Publications: Reston, VA, USA, 2012; pp. 341-348.

52. OGC. The OGC Landinfra Conceptual Model; Open Geospatial Consortium Inc: Wayland, MA, USA, 2014.

53. Aien, A.; Rajabifard, A.; Kalantari, M.; Shojaei, D. Integrating legal and physical dimensions of urban environments. ISPRS Int. J. Geo-Inf. 2015, 4, 1442-1479. [CrossRef]

54. Li, K.-J.; Lee, J.; Zlatanova, S.; Morley, J. Indoorgml SWG. Available online: http:/ /www.opengeospatial. org/projects/groups/indoorgmlswg (accessed on 12 July 2016).

55. Kim, J.-S.; Yoo, S.-J.; Li, K.-J. Integrating indoorgml and citygml for indoor space. In Web and Wireless Geographical Information Systems; Springer: New York, NY, USA, 2014; pp. 184-196.

56. Hwang, J.-R.; Kang, H.-Y.; Choi, J.-W. Development of an editor and a viewer for indoorgml. In Proceedings of the Fourth ACM SIGSPATIAL International Workshop on Indoor Spatial Awareness, New York, NY, USA, 7-9 November 2012. 
57. El-Mekawy, M.; Östman, A.; Hijazi, I. An evaluation of ifc-citygml unidirectional conversion. Int. J. Adv. Comput. Sci. Appl. 2012, 3, 159-171. [CrossRef]

58. Benner, J.; Geiger, A.; Leinemann, K. Flexible Generation of Semantic 3D Building Models. In Proceedings of the 1st international workshop on next generation 3D city models, Bonn, Germany, 21-22 June 2005; pp. 17-22.

59. El-Mekawy, M. Integrating BIM and GIS for 3D City Modelling: The Case of IFC and CityGML; KTH: Stockholm, Sweden, 2010.

60. Isikdag, U.; Zlatanova, S. Towards defining a framework for automatic generation of buildings in citygml using building information models. In 3D Geo-Information Sciences; Springer: Heidelberg, Germany, 2009; pp. 79-96.

61. Hijazi, I.; Ehlers, M.; Zlatanova, S.; Isikdag, U. IFC to citygml transformation framework for geo-analysis: a water utility network case, 3D Geoinfo. In Proceedings of the 4th International Workshop on 3D Geo-Information, Ghent, Belgium, 4-5 November 2009; pp. 123-127.

62. Cheng, J.C.P.; Deng, Y.; Du, Q. Mapping between BIM Models and 3D GIS City Models of Different Levels of Detail. In Proceedings of the 13th International Conference on Construction Applications of Virtual Reality (CONVR 2013), London, UK, 30-31 October 2013.

63. BIMserver. Building Information Model Server. Available online: http://BIMserver.org/ (accessed on 21 August 2016).

64. Beetz, J.; van Berlo, L.; de Laat, R.; van den Helm, P. BIMserver. ORG-An open source IFC model server. In Proceedings of the CIP W78 Conference, Haifa, Israel, 14-16 July 2010.

65. EMF. Eclipse Modelling Framework. Available online: http://www.eclipse.org/modeling/emf/ (accessed on 26 October 2016).

66. DB, B. Open Source Database. Available online: http://www.oracle.com/technetwork/database/ berkeleydb/overview/index.html (accessed on 27 October 2016).

67. IFC Engine Series. Library for Handling IFC Models. Available online: http://www.ifcbrowser.com/ (accessed on 30 October 2016).

68. Haefele, k.-h. Citygml-Developers. Available online: http://www.citygmlwiki.org/index.php/CityGMLDevelopers (accessed on 17 August 2016).

69. Geiger, A.; Benner, J.; Haefele, K.H. Generalization of 3D IFC building models. In 3D Geoinformation Science; Springer: New York, NY, USA, 2015; pp. 19-35.

70. Benner, J.; Geiger, A.; Haefele, K.-H.; Isele, J. Interoperability of geothermal data models. In Proceedings of the World Geothermal Congress, Bali, Indonesia, 25-29 April 2010.

71. Zlatanova, S.; Beetz, J.; Boersma, A.; Mulder, A.; Goos, J. 3D spatial information infrastructure for the port of rotterdam. In Proceedings of the International Workshop on "Global Geospatial Information", Novosibirsk, Russia, 25 April 2013.

72. Kang, T.W.; Hong, C.H. A study on software architecture for effective BIM/GIS-based facility management data integration. Autom. Constr. 2015, 54, 25-38. [CrossRef]

73. Kang, T.W.; Hong, C.H. The architecture development for the interoperability between BIM and GIS. In Proceedings of the 13th International Conference on Construction Applications of Virtual Reality, London, UK, 30-31 October 2013.

74. Safe Software. FME. BC Canada, 2016. Available online: http://www.safe.com/ (accessed on 1 June 2016).

75. ESRI. ArcGIS Data Interoperability. Available online: http://www.esri.com/software/arcGIS/extensions/ datainteroperability (accessed on 18 March 2016).

76. Dale, L. Oracle Spatial Extraction, Transform and Load (etl); Oracle: Tampa, FL, USA, 2009.

77. Boyes, G.; Thomson, C.; Ellul, C. Integrating BIM and GIS: Exploring the use of IFC space objects and boundaries. In Proceedings of the GISRUK 2015, Leeds, UK, 15-17 April 2015; University of Leeds: Leeds, UK, 2015.

78. Zemmouchi-Ghomari, L.; Ghomari, A.R. Reference ontology. In Proceedings of the 2009 Fifth International Conference on Signal-Image Technology \& Internet-Based Systems (SITIS), Marrakesh, Morocco, 29 November-4 December 2009.

79. Cuenca Grau, B.; Horrocks, I.; Kazakov, Y.; Sattler, U. Modular reuse of ontologies: Theory and practice. J. Artif. Intell. Res. 2008, 273-318. 
80. Beetz, J. A scalable network of concept libraries using distributed graph databases. In Proceedings of the Joint ICCCBE 2014 and the 2014 CIB W078 Conference, Orlando, FL, USA, 23-25 June 2014.

81. IFG (IFC for GIS). Ci-3 Industry Foundation Classes for GIS (IFG). Available online: http:/ / www.buildingsmarttech.org/future-extensions/ifc_extension_projects/current/ic3 (accessed on 26 September 2016).

82. IFD (International Framework for Dictionaries). Buildingsmart Data Dictionary. Available online: http:/ / bsdd.buildingsmart.org/\#peregrine/about (accessed on 17 June 2016).

83. Plessers, P.; De Troyer, O.; Casteleyn, S. Understanding ontology evolution: A change detection approach. Web Semant.: Sci. Serv. Agents World Wide Web 2007, 5, 39-49. [CrossRef]

84. Vanlande, R.; Nicolle, C.; Cruz, C. IFC and building lifecycle management. Autom. Constr. 2008, 18, 70-78. [CrossRef]

85. Karan, E.P.; Irizarry, J.; Haymaker, J. BIM and GIS integration and interoperability based on semantic web technology. J. Comput. Civ. Eng. 2015, 30, 04015043. [CrossRef]

86. Karan, E.P.; Irizarry, J. Extending BIM interoperability to preconstruction operations using geospatial analyses and semantic web services. Autom. Constr. 2015, 53, 1-12. [CrossRef]

87. Gröger, G.; Kolbe, T.; Czerwinski, A. Candidate OpenGIS®Citygml Implementation Specification (City Geography Markup Language); Open Geospatial Consortium Inc (OGC): Wayland, MA, USA, 2007.

88. Hagedorn, B.; Dollner, J. Integrating urban GIS, CAD, and BIM data by service-based virtual 3D city models. In Urban and Regional Data Management; Rumor, M., Coors, V., Fendel, E.M., Zlatanova, S., Eds.; Taylor \& Francis: London, UK, 2008; pp. 157-170.

89. Irizarry, J.; Karan, E.P.; Jalaei, F. Integrating BIM and GIS to improve the visual monitoring of construction supply chain management. Autom. Constr. 2013, 31, 241-254. [CrossRef]

90. Niu, S.; Pan, W.; Zhao, Y. A BIM-GIS integrated web-based visualization system for low energy building design. Procedia Eng. 2015, 121, 2184-2192. [CrossRef]

91. Frédéricque, B.; Raymond, K.; Van Prooijen, K. 3D GIS as Applied to Cadastre-A Benchmark of Today's Capabilities; FIG Working Week: Marrakech, Morocco, 2011.

92. Shojaei, D.; Rajabifard, A.; Kalantari, M.; Bishop, I.D.; Aien, A. Design and development of a web-based 3D cadastral visualisation prototype. Int. J. Digit. Earth 2015, 8, 538-557. [CrossRef]

93. Aien, A.; Kalantari, M.; Rajabifard, A.; Williamson, I.; Bennett, R. Utilising data modelling to understand the structure of 3D cadastres. J. Spat. Sci. 2013, 58, 215-234. [CrossRef]

94. Prasad, M. Location Based Services; GIS Developmemt Pvt. Ltd.: Nodia, India, 2002; pp. 3-35.

95. D'Roza, T.; Bilchev, G. An overview of location-based services. BT Technol. J. 2003, 21, 20-27. [CrossRef]

96. Isikdag, U.; Underwood, J.; Aouad, G. An investigation into the applicability of building information models in geospatial environment in support of site selection and fire response management processes. Adv. Eng. Inf. 2008, 22, 504-519. [CrossRef]

97. Li, Y. Building information model for 3D indoor navigation in emergency response. Adv. Mater. Res. 2012, 368, 3837-3840. [CrossRef]

98. Shayeganfar, F.; Anjomshoaa, A.; Tjoa, A. A smart indoor navigation solution based on building information model and google android. In Computers Helping People with Special Needs; Miesenberger, K., Klaus, J., Zagler, W., Karshmer, A., Eds.; Springer: Berlin, Germany, 2008; pp. 1050-1056.

99. Zverovich, V.; Mahdjoubi, L.; Boguslawski, P.; Fadli, F.; Barki, H. Emergency response in complex buildings: Automated selection of safest and balanced routes. Comput.-Aid. Civ. Infrastruct. Eng. 2016, 31, 617-632. [CrossRef]

100. Truijens, M.; Wang, X.; de Graaf, H.; Liu, J. Evaluating the performance of absolute rssi positioning algorithm-based microzoning and rfid in construction materials tracking. Math. Probl. Eng. 2014. [CrossRef]

101. Gwang-Gook, L.; Byeoung-su, K.; Kee-Hwan, K.; Hyoung-ki, K.; Ja-Young, Y.; Jae-Jun, K.; Whoi-Yul, K. Prototype development of a spatial information management system for large-scale buildings. In Proceedings of the FGCNS '08. Second International Conference on Future Generation Communication and Networking Symposia, Hainan, China, 13-15 December 2008; pp. 125-129.

102. Chang, J.-R.; Hsu, H.-M.; Chao, S.-J. Development of a road monitoring and reporting system based on location-based services and augmented-reality technologies. J. Perform. Constr. Facil. 2011, 26, 812-823. [CrossRef]

103. Shahi, A.; West, J.S.; Haas, C.T. Onsite 3D marking for construction activity tracking. Autom. Constr. 2013, 30, 136-143. [CrossRef] 
104. Mahamadu, A.M.; Mahdjoubi, L.; Booth, C. Challenges to BIM-cloud integration: Implication of security issues on secure collaboration. In Proceedings of the 2013 IEEE 5th International Conference on Cloud Computing Technology and Science (CloudCom), Bristol, UK, 2-5 December 2013; pp. 209-214.

105. Sengupta, S.; Kaulgud, V.; Sharma, V.S. Cloud computing security-trends and research directions. In Proceedings of the 2011 IEEE World Congress on Services (SERVICES), Washington, DC, USA, 4-9 July 2011; pp. 524-531.

106. Howard, R.; Björk, B.-C. Building information modelling-experts' views on standardisation and industry deployment. Adv. Eng. Inf. 2008, 22, 271-280. [CrossRef]

107. Lemer, A. Progress toward integrated infrastructure-assets-management systems: GIS and beyond. In Proceedings of the Innovations in Urban Infrastructure Seminar of the APWA International Public Works Congress, Las Vegas, NV, USA, 14-17 September 1998.

108. Park, T.; Kang, T.; Lee, Y.; Seo, K. Project cost estimation of national road in preliminary feasibility stage using BIM/GIS platform. In Computing in Civil and Building Engineering (2014); ASCE: Reston, VA, USA, 2014; pp. 423-430.

109. Krämer, I.M.; Peris, M.S.B. Usage of geographic information systems (GIS) and building information models (BIM) in facility management at botanic garden berlin. ING IN 2014, 224, 224-234.

110. Huber, D.; Akinci, B.; Oliver, A.; Anil, E.; Okorn, B.; Xiong, X. Methods for automatically modeling and representing as-built building information models. In Proceedings of the NSF CMMI Research Innovation Conference, Atlanta, GA, USA, 4-7 January 2011.

111. Hichri, N.; Stefani, C.; De Luca, L.; Veron, P. Review of the 'as-built BIM'approaches. In Proceedings of the International Archives of the Photogrammetry, Remote Sensing and Spatial Information Sciences, XL, Trento, Italy, 25-26 February 2013; pp. 107-112.

112. Dore, C.; Murphy, M. Integration of historic building information modeling (hBIM) and 3D GIS for recording and managing cultural heritage sites. In Proceedings of the 2012 18th International Conference on Virtual Systems and Multimedia (VSMM), Milan, Italy, 2-5 September 2012; pp. 369-376.

113. SanJosé-Alonso, J.; Finat, J.; Pérez-Moneo, J.; Fernández-Martín, J.; Martínez-Rubio, J. Information and knowledge systems for integrated models in cultural heritage. In Proceedings of the 3rd ISPRS International Workshop 3D-ARCH 2009, Trento, Italy, 25-28 February 2009; p. 5.

114. Centofanti, M.; Continenza, R.; Brusaporci, S.; Trizio, I. The Architectural Information System Siarch3D-Univaq for Analysis and Preservation of Architectural Heritage. ISPRS Arch. Photogramm. Remote Sens. Spat. Inf. Sci. 2011, 38, 5-16. [CrossRef]

115. Yang, W.-B.; Yen, Y.-N.; Cheng, H.-M. An integrated management system for historical buildings: The case study of dihua historical street districts in Taiwan. In Progress in Cultural Heritage Preservation; Ioannides, M., Fritsch, D., Leissner, J., Davies, R., Remondino, F., Caffo, R., Eds.; Springer: Heidelberg, Germany, 2012; pp. 594-601.

116. Li, H.; Chan, N.; Huang, T.; Guo, H.; Lu, W.; Skitmore, M. Optimizing construction planning schedules by virtual prototyping enabled resource analysis. Autom. Constr. 2009, 18, 912-918. [CrossRef]

117. Sebt, M.; Karan, E.P.; Delavar, M. Potential application of GIS to layout of construction temporary facilities. Int. J. Civ. Eng. 2008, 6, 235-245.

118. Su, X.; Andoh, A.r.; Cai, H.; Pan, J.; Kandil, A.; Said, H.M. GIS-based dynamic construction site material layout evaluation for building renovation projects. Autom. Constr. 2012, 27, 40-49. [CrossRef]

119. Bansal, V.; Pal, M. Potential of geographic information systems in building cost estimation and visualization. Autom. Constr. 2007, 16, 311-322. [CrossRef]

120. Zhong, D.; Li, J.; Zhu, H.; Song, L. Geographic information system-based visual simulation methodology and its application in concrete dam construction processes. J. Constr. Eng. Manag. 2004, 130, 742-750. [CrossRef]

121. Bansal, V. Application of geographic information systems in construction safety planning. Int. J. Project Manag. 2011, 29, 66-77. [CrossRef]

122. Hollands, R.G. Will the real smart city please stand up? Intelligent, progressive or entrepreneurial? City 2008, 12, 303-320. [CrossRef]

123. Komninos, N. Intelligent Cities: Innovation, Knowledge Systems, and Digital Spaces; Taylor \& Francis: London, UK; New York, NY, USA, 2002.

124. Neirotti, P.; De Marco, A.; Cagliano, A.C.; Mangano, G.; Scorrano, F. Current trends in smart city initiatives: Some stylised facts. Cities 2014, 38, 25-36. [CrossRef] 
125. Thiis, T.K.; Hjelseth, E. Use of BIM and GIS to enable climatic adaptions of buildings. In Ework and Ebusiness in Architecture, Engineering and Construction; Taylor \& Francis: London, UK, 2008; pp. 409-417.

126. Bansal, V.K.; Pal, M. Extended GIS for construction engineering by adding direct sunlight visualisations on buildings. Constr. Innov.: Inf. Process Manag. 2009, 9, 406-419. [CrossRef]

127. Strzalka, A.; Bogdahn, J.; Coors, V.; Eicker, U. 3D city modeling for urban scale heating energy demand forecasting. HVACER Res. 2011, 17, 526-539.

128. Strømann-Andersen, J.; Sattrup, P.A. The urban canyon and building energy use: Urban density versus daylight and passive solar gains. Energy Build. 2011, 43, 2011-2020. [CrossRef]

129. Castro-Lacouture, D.; Quan, S.J.; Yang, P.P.-J. GIS-BIM framework for integrating urban systems, waste stream and algal cultivation in residential construction. In Proceedings of the 31st International Symposium on Automation and Robotics in Construction and Mining (ISARC 2014), Sydney, Australia, 9-11 July 2014.

130. Di Giulio, R.; Bizzarri, G.; Turillazzi, B.; Marzi, L.; Quentin, C. The BIM-GIS model for eebs integrated in healthcare districts: An italian case study. Sustain. Places 2015, 2015, 111-121.

131. Zhou, W.; Whyte, J.; Sacks, R. Construction safety and digital design: A review. Autom. Constr. 2012, 22, 102-111. [CrossRef]

132. Elbeltagi, E.; Hegazy, T.; Eldosouky, A. Dynamic layout of construction temporary facilities considering safety. J. Constr. Eng. Manag. 2004, 130, 534-541. [CrossRef]

133. Zhang, J.; Hu, Z. BIM-and 4d-based integrated solution of analysis and management for conflicts and structural safety problems during construction: 1. Principles and methodologies. Autom. Constr. 2011, 20, 155-166. [CrossRef]

134. Zhang, S.; Teizer, J.; Lee, J.-K.; Eastman, C.M.; Venugopal, M. Building information modeling (BIM) and safety: Automatic safety checking of construction models and schedules. Autom. Constr. 2013, 29, 183-195. [CrossRef]

135. Tashakkori, H.; Rajabifard, A.; Kalantari, M. A new 3D indoor/outdoor spatial model for indoor emergency response facilitation. Build. Environ. 2015, 89, 170-182. [CrossRef]

136. Kim, J.I.; Koo, B.; Suh, S.; Suh, W. Integration of BIM and GIS for formal representation of walkability for safe routes to school programs. KSCE J. Civ. Eng. 2016, 20, 1669-1675. [CrossRef]

137. Fenton, G.A.; Griffiths, D.V. Risk Assessment in Geotechnical Engineering; John Wiley \& Sons Incorporated: New York, NY, USA, 2008.

138. Hack, R. Integration of surface and subsurface data for civil engineering. In Proceedings of the 1st International Conference (ICITG), IOS, Amsterdam, The Netherlands, 16-17 September 2010.

139. Staveren, M.V. Uncertainty and Ground Conditions: A Risk Management Approach; Butterworth-Heinemann: Oxford, UK, 2006.

140. Tegtmeier, W.; Zlatanova, S.; van Oosterom, P.J.M.; Hack, H.R.G.K. 3D-GEM: Geo-technical extension towards an integrated 3D information model for infrastructural development. Comput. Geosci. 2014, 64, 126-135. [CrossRef]

141. Cerovsek, T. A review and outlook for a 'building information model'(BIM): A multi-standpoint framework for technological development. Adv. Eng. Inf. 2011, 25, 224-244. [CrossRef]

(C) 2017 by the authors; licensee MDPI, Basel, Switzerland. This article is an open access article distributed under the terms and conditions of the Creative Commons Attribution (CC BY) license (http:/ / creativecommons.org/licenses/by/4.0/). 